\title{
A Comparison of Three Methods for Estimat- ing Forage Disappearance
}

\author{
S.H. SHARROW AND I. MOTAZEDIAN
}

\begin{abstract}
Three methods of calculating forage disappearance from forage standing crop present on mowed versus protected plots were compared to the actual amount of forage harvested from mowed plots. The method most widely used by range scientists, the difference method, displayed a marked tendency to overestimate forage disappearance during periods of rapid plant growth or when plots were protected for more than 3 weeks. More accurate estimates of forage disappearance were generally obtained using formulae suggested by Linehan et al. (1947) and Bosch (1956) than could be obtained by the difference method.
\end{abstract}

The movable cage technique (Brown 1954, Pieper 1978) is commonly used to estimate forage production and utilization of forage by livestock in range and pasture studies (Pieper 1978). While forage disappearance-the difference in standing phytomass between grazed and protected plots-may yield acceptably accurate estimates of forage intake by livestock in some cases (Walter ane Evans 1979), it substantially overestimates intake in other cases (Allison and Kothmann 1979, Joint Committee 1943, Linehan et al. 1946, 1947). Linehan et al. (1952) demonstrated that estimated forage intake of cattle was from 7 to $49 \%$ higher when based upon forage disappearance than when calculated from animal performance. This occurred in spite of the fact that a relatively short (6- to 12-day) grazing period was employed. Overestimates may reflect forage lost to trampling (Laycock et al. 1972, Pearson 1975) or that consumed by herbivores other than livestock (Pearson 1975). Higher plant growth rates on protected plots compared to grazed plots (Cowlishaw 1951, Grelen 1967, Heady 1957) may also contribute to overestimation of forage intake.

Both Linehan et al. (1947) and Bosch (1956) have attempted to reduce this bias by modifying the formula used to calculate forage intake from data obtained by the movable cage technique. An extensive data set was used in deriving the proposed formulae. However, few data are available to validate these formulae other than those presented by Linehan et al. (1952) and Bosch (1956) themselves.

The purpose of this paper is to compare estimates of forage disappearance (harvest) obtained by direct harvest of perennial ryegrass-subclover swards to those calculated using (1) the conventional "difference" formula, (2) Linehan et al.'s (1947) formula, and (3) Bosch's (1956) formula.

\section{Materials and Methods}

The study was conducted on a perennial ryegrass (Lolium perenne)-subclover (Trifolium subterraneum) hill pasture $1 \mathrm{~km}$ west of Corvallis, Ore. Elevation is approximately $100 \mathrm{~m}$. Annual precipitation is approximately $100 \mathrm{~cm}$.

A factorial arrangement of 12 treatments consisting of 3 defoliation intensities $(4,5.5$, and $7-\mathrm{cm}$ clipping height above the soil surface) and 4 defoliation frequencies (clipped every 1, 3, 5, or 7 weeks) were monitored using plots of $4 \mathrm{~m}^{2}$ each in spring 1981. All

\footnotetext{
Authors are associate professor and graduate student, respectively, Department of

Rangeland Resources, Oregon State University, Corvallis 97331.

This report was submitted as Technical Paper No. 6208, Oregon Agricultural

Experiment Station, Corvallis.

Manuscript received July 21, 1982.
}

treatment combinations were replicated 3 times. Forage harvested on each date was collected by mowing the appropriate plots with a rear-bagging rotary lawn mower. The entire contents of the mower bag were weighed and a grab sample obtained for dry matter determination. Total forage harvested was corrected to an ovendry matter basis using the percent dry matter calculated from field weights of grab samples d ried for 48 hours at $50^{\circ} \mathrm{C}$. Forage remaining immediately following mowing was estimated by clipping 1, $0.08-\mathrm{m}^{2}$ quadrat to ground level in each plot. Samples were dried in an oven at $50^{\circ} \mathrm{C}$ for 48 hours, then weights recorded. Actual forage removed from plots clipped each week (disappearance) was determined for the first 3 weeks (24 March to 14 April), the second 3 weeks (14 April to 5 May), the first 5 weeks (24 March to 28 April), and the first 7 weeks (24 March to 12 May) by summing the individual weekly harvests for each defoliation intensity.

Estimates of forage disappearance were calculated by comparison of plots mowed weekly to "protected" plots which were mowed only once at the end of a 3-, 5-, or 7-week sampling period. Three methods were employed: (1) the conventional "difference" method (Milner and Hughes 1970, Pieper 1978, Joint Committee 1943): harvest $=d-f ;$ (2) Linehan et al.'s (1947) formula:

$$
\begin{aligned}
& \text { harvest }=(c-f) \frac{\log d-\log f}{\log c-\log f} \quad ;(3) \text { Bosch's (1956) formula: } \\
& \text { harvest }=(c-f) \frac{d-c}{2} \quad \text { where } \\
& c= \text { forage standing crop on both mowed and protected plots at the } \\
& \text { commencement of the sample period }
\end{aligned}
$$

Estimates of forage disappearance were compared by Tukey's w procedure using $P<0.05$ as the criterion for significance.

\section{Results and Discussion}

Estimates of forage disappearance calculated from the 3 formulae are presented in Table 1 . It is interesting to note that in all cases, the protected plots produced more forage than did plots which were clipped each week. This observation agrees well with those of other workers who have reported increased total dry matter yield from swards as defoliation frequency decreased (Brougham 1959, Cook and Stoddart 1953, Jones 1974, Ludlow and CharlesEdwards 1980). This result is believed to reflect increased leaf area accumulated on plots as frequency of defoliation decreases (Ludlow and Charles-Edwards 1980, Smetham 1977). Similar growth rates of both protected and grazed plots are generally assumed in calculating forage yield and forage disappearance by the "difference" method. Therefore, increased growth on protected relative to grazed plots should result in overestimation of forage available on grazed plots. This appeared to be the case. Both Grelen (1967) and Wagner et al. (1950) have reported overestimates of pasture pro- 
Table 1. Estimates of forage disappearance $(\mathrm{kg} / \mathrm{ha})$ calculated from phytomass parameters (C,F,D) using 4 different methods.1

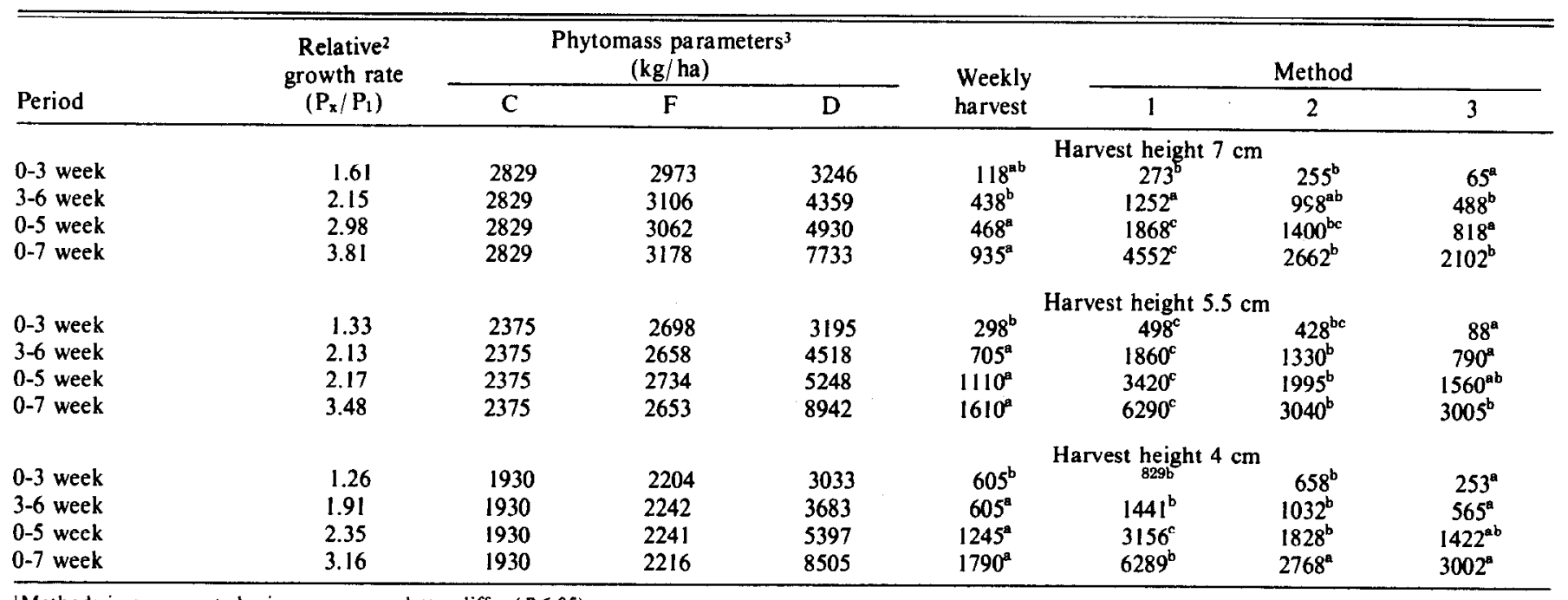

1Methods in a row not sharing a common letter differ $(P<.05)$.

${ }^{2} P_{x} / P_{1}$ is the ratio of standing phytomass on plots mowed once at the end of $x$ weeks/cumulative total yield of plots mowed weekly for the same period.

${ }^{3} \mathrm{C}=$ Forage standing crop at the beginning of the sampling period.

$F=$ Forage standing crop on weekly-mowed plots at the end of the sampling period.

$\mathrm{D}=$ Forage standing crop on protected (unmowed) plots at the end of the sampling period.

duction obtained using the movable cage technique.

Overestimates of forage a vailable may result in overestimates of forage disappearance, utilization, and forage intake when calculations are made using the standard "disappea rance" method $(d-f)$. The "difference" method (method 1) consistently overestimated forage disappearance in this trial (Table 1). Forage disappearance calculated by method 1 ranged from $29 \%$ to $387 \%$ higher than the actual value obtaincd from cumulative harvest. The difference method was most accurate during the first 3 weeks of the trial, a period of relatively slow growth. Accuracy tended to be less during periods of rapid growth, such as the 3- to 6-week period. In addition, length of the period of protection and intensity of defoliation also affected accuracy. Overestimation was observed to be greatest when the period of plot protection was long and when potential for growth was greatest (stubble height was highest). These observations agree with the general properties of the difference method as discussed by Smith et al. (1962) and Milner and Hughes (1970). Milner and $H$ ughes (1976) suggested that if cages must be left in place for long periods of time (more than I month), Linehan et al's (1947) formula (method 2) may yield more accurate results than the conventional "difference" calculation.

Lack of agreement between forage disappea rance as calculated by the "disappearance" method and forage consumption by livestock calculated from animal performance data led Linehan et al. (1947) to propose a new formula for calculating forage intake from movable cage data. Their formula is designed to avoid problems of differential growth between caged versus grazed plots by use of an assumed relationship between the amount of forage consumed by livestock, sward growth rate, and standing sward phytomass at any point in time. The integration of this relationship over time yielded an estimate of forage consumption by livestock for that period. The resulting formula (method 2) has some rather interesting properties. Although method 2 generally overestimated forage disappearance (Table 1), it tended to be more accurate than method 1 . In addition, it appeared to be relatively insensitive to the length of the sampling period, working equally well when plots were protected for 7 weeks as it did when plots were protected for only 3 weeks. In this regard, method 2 appeared superior to method 1. Method 2 does, however, have a definite mathematical peculiarity. In the event that grazed sward phytomass remains stable over time (i.e. $c=f)$, the formula $(c-f)$.

$\underline{(\log d-\log f)}$

$(\log c-\log f) \quad$ will always predict zero forage disappear- ance regardless of the actual amount of forage produced and consumed. This renders method 2 unusable for instances in which forage production equals forage consumption.

Using data from Linehan et al. (1947), Bosch (1956) developed a formula which he contended yielded similar estimates of forage disappearance to those obtained from the more complicated formula of Linehan et al. (1947). Besides being easier to calculate, Bosch's (1956) formula allows calculation of forage consumed by livestock even when forage production equals forage consumption. Although the derivation of method 3 is not discussed by Bosch (1956), forage consumption appears to be estimated as the change in standing phytomass corrected for any growth which occurred during the grazing period. Growth on the grazed plots is estimated as one half that on protected plots (i.e. $\frac{d-c}{2}$ ). It is not clear how this assumption of growth rate being twice as high on protected as on grazed plots was determined. While this relationship was true for data presented by Linehan et al. (1947), it was not true for our data (Table 1). Growth rate ratios for protected/mowed plots were less than 2 in the early spring (0- to 3-week period) when growth was slow. Method 3 tended to underestimate forage disappearance at that time. When the growth rate ratio was approximately 2 (3- to 6-week period), method 3 yielded fairly accurate estimates of forage disappearance. Growth rate ratios and the tendency of method 3 to overestimate forage disappearance increased with increasing period of protection of unmowed plots (grazing period). In spite of problems associated with the use of a constant relative growth rate between grazed and ungrazed plots, method 3 was consistently the most accurate formula of the 3 evaluated for predicting forage disappearance. In addition, although more sensitive to the length of the protection period for ungrazed plots than method 2 , it was much Iss sensitive than was method 1.

\section{Conclusions}

Data presented in this paper support Linehan et al.'s (1952) view that the difference method (method 1 ) tends to overestimate forage disappearance. Overestimates were most pronounced during periods of rapid plant growth or where unmowed plots were protected for long periods of time. Furthermore, since no cages or livestock were employed in this study, overestimates of forage disappearance cannot be attributed to microclimatic effects of cages or to 
trampling losses. Differences in plant growth on protected compared to mowed plots, possibly due to a higher leaf area index on protected plots, are believed to be the primary cause of observed overestimation using the difference method.

Both method 2 (Linehan et al. 1947) and method 3 (Bosch 1956) generally produced more accurate estimates of forage disappearance than those obtained by the more commonly used difference method. While method 2 was the most precise, method 3 was the most accurate. Of the two formulae, method 2 was least sensitive to the length of time plots were protected. These data suggest that either method 2 or method 3 should be adopted in preference to the difference method when substantial amounts of plant growth are expected to occur during the sampling period.

While adoption of methods 2 or 3 in preference to method 1 can ameliorate the effects of differential growth between grazed and protected plots, it is not a solution to the problem. All 3 methods of calculation examined displayed a marked tendency to overestimate forage disappearance when unmowed reference plots were protected for more than 3 weeks. It appears, therefore, the reference plots should be protected for as short a time as practical regardless of the method of calculation employed to estimate forage disappearance. Furthermore, the magnitude of overestimation observed in this study casts doubt upon the usefulness of forage disappearance or utilization estimates which are derived from comparison of grazed plots to reference plots which have been protected for long periods of time.

\section{Literature Cited}

Allison, C.D., and M.M. Kothmann. 1979. Effects of level of stocking pressure on forage intake and diet quality of range cattle. Proc,, West. Sect. Amer. Soc. of Anim. Sci. 30:174-178.

Bosch, S. 1956. The determination of pasture yield. Neth. J. Agr. Res. 4:305-312.

Brougham, R.W.1959. The effects of frequency and intensity of grazing on the productivity of a pasture of short-rotation ryegrass and red and white clover. N.Z. J. Agr. Res. 2:1232-1248

Brown, D. 1954. Methods of surveying and measuring vegetation. Commonwealth Bureau of Pastures and Field Crops. Bull. 42.

Cook, C.S., and L.A. Stoddart. 1953. The quandary of utilization and preference. J. Range Manage. 6:329-335.
Cowlishaw, S.J. 1955. The effect of sampling cages on the yields of herbage. J. Brit. Grassld. Soc. 6:179.

Grelen, H.E. 1967. Comparison of cage methods for determining utilization on pine-bluestem range. J. Range Manage. 20:94-96.

Heady, H.F. 1957. The effect of cages on yield and composition in the California annual type. J. Range Manage. 10:175.

Joint Committee of American Society of Agronomy, American Dairy Science Association, and American Society of Animal Production. 1943. Preliminary report on pasture investigations technique. J. Dairy Sci. 26:353-369.

Jones, R.J. 1974. Effect of an associate grass, cutting interval, and cutting height on yield and botanical composition of sirato pastures in a subtropical environment. Aust. J. Exp. Agr. Anim. Husb. 14:334-342.

Laycock, W.A., H. Buchanan, and W.C. Krueger. 1972. Three methods of determining diet, utilization, and trampling damage on sheep ranges. J. Range Manage. 25:352-356.

Linehan, P.A., and J. Lowe. 1946. The output of pasture and its measurement. J. Brit. Grassld. Soc. 1:1-29.

Linehan, P.A., J. Lowe, and R.H. Stewart. 1947. The output of pasture and its measurement. Part 2. J. Brit. Grassld. Soc. 2:145-168.

Linehan, P.A., J. Lowe, and R.H. Stewart. 1952. The output of pasture and its measurement. Part 3. J. Brit. Grassid. Soc. 7:73-98.

Ludlow, M.M., and D.H. Charles-Edwards. 1980. Analysis of the regrowth of a tropical grass-legume sward subjected to different frequencies and intensities of defoliation. Aust. J. Agr. Res. 31:673-692.

Milner, C., and R.E. Highes. 1968. Methods for the measurement of the primary production of grassland. Int. Biol. Program Handbook No. 6 Blackwell Sci. Pub., Oxford.

Pearson, H.A. 1975. Herbage disappearance and grazing capacity determinations of southern pine-bluestem range. J. Range Manage. 28:71-73.

Pieper, R.D. 1978. Measurement techniques for herbaceous and shrubby vegetation. Mimeograph Services, New Mexico State University, Las Cruces.

Smethan, M.L. 1977. Grazing management, p. 179-228. In: R.H.M. Langer (editor), Pastures and Pasture Plants. A.H. and A.W. Reed, London.

Smith, D.R., P.O. Currie, J.V. Basile, and N.C. Frischknecht. 1962. Measurement and evaluation of range use by livestock and game. In: Range research methods. USDA Forest Service Misc. Pub. 940.

Wagner, R.E., M.A. Hein, J.B. Shepherd, and R.E. Ely. 1950. A comparison of cage and mower strip methods with grazing results in determining production of dairy pastures. Agron. J. 42:487-491.

Walter, R.J.K., and E.M. Evans. 1979. Evaluation of a sward sampling technique for estimating herbage intake by grazing sheep. Grass and Forage Sci. 34:37-45.

\section{Telecommunications Available}

Authors who have access to word processors and computers with telecommunication capability may be able to access the Journal of Range Management office either through DIALCOM or by direct machine-to-machine communication. Although manuscripts cannot be submitted electronically at this time, communications on page proofs may be feasible in some instances. It will be necessary to contact the telecommunications operator first and set up a test communication before sending material. 